\title{
Co-rumination, anxiety, and maladaptive cognitive schemas: when friendship can hurt
}

This article was published in the following Dove Press journal:

Psychology Research and Behavior Management

\section{Leonardo Carlucci \\ Ines D'Ambrosio \\ Marco Innamorati \\ Aristide Saggino \\ Michela Balsamo}

Department of Psychological Sciences, Health and Territory, "G. d'Annunzio"

University, Chieti, Italy
Correspondence: Leonardo Carlucci Department of Psychological Sciences, Health and Territory, "G. d'Annunzio" University, Via dei Vestini, 3 I c/o ex-Rettorato, 66100 Chieti, Italy

Tel +39 087I 3555309

Fax +39 087I 3555314

Email I.carlucci@unich.it
Background: This study investigated maladaptive cognitive schemas as mediators of the relationship between co-rumination and anxiety.

Methods: Self-report measures of co-rumination, trait cognitive and somatic anxiety, and early maladaptive cognitive schemas were provided to a nonclinical sample of 461 young adults. Mediation of co-rumination and trait somatic and cognitive anxiety by each early maladaptive schema domain was tested using nonparametric, bootstrap-based resampling.

Results: Significant associations between co-rumination and trait and cognitive anxiety were mediated by schema domains related to Rejection and Disconnection, Overvigilance and Inhibition, and Impaired Autonomy. The association between co-rumination and somatic anxiety was mediated by domains related to Rejection and Disconnection and Impaired Autonomy.

Conclusion: The results of this study showed that those who engage in co-rumination, potentially resulting in clinical levels of anxiety, might benefit from treatment that focuses on themes of rejection sensitivity and belonging, beliefs about autonomy, and when the anxiety is more cognitive, treatment that focuses on hypercriticalness and emotional inhibition too.

Keywords: anxiety, communication, domain, mediation, adults

\section{Background}

Co-rumination is defined as extensive and frequent discussion, speculation, and focus on negative feelings related to personal problems with a close friend or friends. It typically entails rehashing the same problems, mutual encouragement of self-disclosure, and focusing on possible causes, implications, and negative feelings surrounding problems. ${ }^{1,2}$ Co-rumination might, for example, consist of a pair of friends repeatedly discussing a quarrel with a boyfriend or girlfriend, including framing the problem from every point of view, brooding on the negative consequences and emotions generated by the event, and actively inciting one another to continue the discussion. Co-rumination often entails speculating and dwelling on small and/or unknown possibilities related to a problem rather than engaging in active problem solving.

Literature suggests that co-rumination is simultaneously related to both positive and negative outcomes. On the positive side, co-rumination has been linked with friendship closeness, perceptions of friendship quality, and greater job satisfaction. ${ }^{1-3}$ On the negative side, co-rumination has been associated with heightened concurrent and prospective internalizing symptoms (including anxiety and depressive symptoms), particularly among females. . $^{1,2,4}$

Much like rumination or other forms of perseverative thought, ${ }^{8}$ co-rumination is a process that can create vulnerability for and/or sustain/exacerbate the pathophysiology 
of emotional disorders. ${ }^{9}$ Co-rumination might act as a dysfunctional coping style engaged to manage negative emotions, cognitions, and memories associated with internalizing symptoms. ${ }^{1,2}$ For example, co-rumination operates as a mediator variable in depression and anxiety contagion effects among children and adolescents, especially in girls. ${ }^{10}$

Despite a relative dearth of examination, it stands to reason that co-rumination can be present within a general cognitive model of psychopathology. ${ }^{11}$ As such, the co-rumination may be an expression of a schema and/or serve to reinforce certain schema (an organized pattern of thought that provides meaning, context, and prediction for experiences). ${ }^{11}$ Several studies to date have examined the relation of co-rumination to internalizing symptoms without placing the processes within a cognitive framework. Originally, Beck proposed that one cause of anxiety might be a function of alterations to cognitive schema. ${ }^{11,12}$ More recently, Beck and Haigh argued that the development of schema is intimately involved in the onset and maintenance of many psychological disorders. ${ }^{11}$ Schema theory, that evolved from Beck's original cognitive theory, offers an explanation of the developmental origins of schema. ${ }^{12,13}$ According to Young et al, schema are defined as broad, pervasive themes or patterns regarding self and relationships with others. ${ }^{13}$ Typically, schemas include cognitive and emotional elements, bodily sensations, and memories. They are developed during childhood or adolescence and are elaborated over time.
As described by Beck and Haigh, the theory that maladaptive schema results from childhood adversity was likely influenced by early developmental work conducted by Piaget and Warden. ${ }^{11,13,14}$

Young et al focused on the developmental origins of schema, at least partially, as a function of their efforts to treat complex emotional disorders. ${ }^{13}$

A taxonomy of 18 "early maladaptive schemas" (EMS) has been developed, with each schema differing with regard to its cognitive content. The Young Schema Questionnaire (YSQ) was developed to assess EMS. ${ }^{15}$ The 18 EMSs have been divided into five umbrella categories, known as schema domains. The schema domains are: 1) Disconnection/Rejection; 2) Impaired Autonomy/performance; 3) Impaired Limits; 4) Other-Directedness; and 5) Overvigilance/Inhibition. In Table 1, a brief description of each schema domain is reported.

These domains are not mutually exclusive, and a given individual may exhibit multiple EMSs, theoretically leading to more pronounced psychological deficits.

EMS could be conceptualized as pervasive and character traits or dispositional characteristics, which results from the interaction between a child's temperament and environmental experiences. ${ }^{16,17}$ They operate on the deepest level of cognition, outside of awareness, and make the subject psychologically vulnerable to develop anxiety, depression,

Table I Description of the five Young schema domains

\begin{tabular}{|c|}
\hline $\begin{array}{l}\text { Disconnection and Rejection domain is predicted by the inability to establish secure and fulfilling relationships because persuaded that the needs for } \\
\text { security, safety, stability, acceptance, and respect will not be met in a predictable manner. Typical family origin is instable (Abandonment); abusive } \\
\text { (Mistrust/Abused); cold (Emotional Deprivation); too demanding (Defectiveness); lonely (Social Isolation). }\end{array}$ \\
\hline $\begin{array}{l}\text { Impaired Autonomy and Performance domain take into consideration the role of expectations about oneself/environment to interfere with one's } \\
\text { perceived ability/performance to separate (ie, separate from the parental figures), function independently. Typical family origin is unable to handle } \\
\text { one's everyday responsibilities in a competent manner (Dependence); undermining of child's confidence (Vulnerability to Harm); excessively } \\
\text { involved emotionally (Enmeshment); failing to reinforce child for performing competently outside family context (Failure). }\end{array}$ \\
\hline $\begin{array}{l}\text { Impaired Limits domain represent the difficulty into respecting the social and interpersonal rules, cooperating, making commitments, and reach } \\
\text { realistic personal or long-term goals. } \\
\text { Typical family origin is permissiveness, lack of direction or characterized by excessive competitiveness, and an inappropriate sense of superiority } \\
\text { (Entitlement/Grandiosity); pervasive difficulty or refusal to exercise sufficient self-control and frustration tolerance (Insufficient Self-Control). }\end{array}$ \\
\hline $\begin{array}{l}\text { Other-Directedness domain represents the systematic tendency to pay too much attention to other's needs, at the expense of one's own. This is } \\
\text { characterized by an excessive focus on the desires, feelings of others, in order to gain love/approval or avoid anger. } \\
\text { Typical family origin is based on conditional acceptance (Subjugation); on voluntarily meeting the needs of others, to prevent causing pain to } \\
\text { others, and to avoid guilt from feeling selfish (Self-Sacrifice); characterized by an overemphasis on status/money, as a means of gaining approval and } \\
\text { attention (Approval-Seeking). }\end{array}$ \\
\hline $\begin{array}{l}\text { Overvigilance and Inhibition domain shows the tendency on suppressing one's impulses, and choices rigid, internalized rules and expectations about } \\
\text { performance/behavior, often at the expense of happiness, self-expression, and health. } \\
\text { Typical family origin is focused on the negative aspects of life, ie, pain, humiliation, conflict, or guilt (Negativity); difficulty expressing vulnerability or } \\
\text { communicating freely about one's feelings and needs (Emotional Inhibition); meet very high internalized standards of behavior and performance, to } \\
\text { avoid criticism (Unrelenting Standards); difficulty forgiving mistakes and intolerance/punitive against errors (Punitiveness). }\end{array}$ \\
\hline
\end{tabular}


and other internalizing symptoms. ${ }^{18}$ EMSs are thought to be trait like, ${ }^{13,19}$ in that they are stable over time. ${ }^{20}$ When certain schemas are triggered, the individual may respond to them adopting a dysfunctional coping style, such as co-rumination, that perpetuates these schemas. ${ }^{13}$

A relatively broad body of literature has supported the existence and developmental origins of EMSs in personality disorders, as well as in mood disorders. ${ }^{21-23}$ Various studies have examined the EMSs associated with anxiety disorders among youth, ${ }^{24}$ adults, ${ }^{25}$ and older adults. ${ }^{26}$ Most EMSs are elevated in anxiety disorders, although the core EMS appears to vary as a function of specific anxiety disorders. ${ }^{27-35}$

Recent studies have underlined that social anxiety (SA) and obsessive-compulsive disorder were predicted by three of the schema domains (Disconnection/Rejection, Impaired Autonomy and performance, and Other-Directedness), ${ }^{28,36,37}$ panic attacks disorder (PAD) was activated by the Impaired Autonomy and Other-Directedness domains; generalized anxiety disorder (GAD) symptomatology and severity were correlated with the Impaired Autonomy, Overvigilance/ Inhibition, and Other-Directedness domains. ${ }^{38}$ Taken together, these results showed that several EMSs are highly activated in a wide range of anxiety disorders, and that the EMSs underline chronic symptoms of anxiety, as suggested by Young et al. ${ }^{13}$

As EMSs play a relevant role of activation in the onset of anxiety disorders, they have been hypothesized to play a similar role in trait anxiety, since anxiety can be conceptualized as a continuum that ranges from state-trait personality to clinical anxiety. ${ }^{39-43}$ Indeed, state-trait anxiety represents "a continuum of increasing intensity on which low scores represent calm, intermediates were associated to worry, and elevated reflect intense fear." ${ }^{4}$

Trait anxiety refers to relatively stabilizing individual differences that characterize people's anxiety or general feeling of anxiety. ${ }^{45}$ Trait anxiety measures can predict both the magnitude of state anxiety reactions, and particular stressful circumstances under which such state anxiety reactions will occur. A person with a high trait test anxiety score would be expected to become more state anxious than a person with low trait test anxiety, specifically in test situations. ${ }^{46}$

In other words, trait vulnerability to the development of anxiety disorders would consist in less intense dysregulation of anxious states than that reported in a clinical anxiety disorder. $^{47}$

Presumably, to the extent certain schemas are triggered, one subject may respond to it co-ruminating with close friends, and this, on one hand, perpetuates the schemas and, on the other hand, leads him/her to more easily experience anxiety states, reinforcing his/her anxiety trait.

The general cognitive model may constitute a valuable framework to understand underlying processes mediating the relationship between perseverative thought which can be either constructive or unconstructive (eg, co-rumination) in young adults, for whom engagement in maladaptive cognitive processes may reinforce cognitive biases, leading to the onset of anxiety symptoms. ${ }^{11}$

Since anxiety is known to present differently in anxiety symptom profiles, subjective experience, and even response to treatment, cognitive and somatic symptom clusters were examined. ${ }^{48-51}$

While the cognitive anxiety cluster aims to capture features of anxiety that are directly related to thoughts (eg, worry, intrusive thoughts, and difficulty in concentrating), the somatic cluster attempts to capture features that are directly related to physical experiences (eg, sweating, palpitations, and muscle tension). ${ }^{46}$

Among all the EMSs, the Impaired Autonomy domain (which includes vulnerability to harm or illness schema) has been identified to have a central role in the activation of somatic anxiety. Indeed, it has been associated with GAD and PAD symptomatology, ${ }^{23}$ and pain catastrophizing. ${ }^{52,53}$ Patients with PAD or GAD have been found to be more sensitive to bodily changes (ie, heart rate) and less accurate in their perception of bodily states than non-anxious individuals. ${ }^{54}$

Furthermore, Overvigilance/Inhibition and OtherDirectedness domains have been shown to have a central role in the activation of the cognitive trait anxiety. ${ }^{55}$ In fact, maladaptive cognitive schemas related to perfectionism, such as Unrelenting Standards schema, Self-Sacrifice, and Negativity schema, characterize people who are prone to excessive and pathological worry and uncertainty in the problem-solving process. ${ }^{55}$

This study aimed to explore the role of schema domains in the association between co-rumination and trait anxiety, in both cognitive and somatic dimensions. We expected that the significant relation between co-rumination and trait anxiety would be, at least partially, explained by specific EMSs. Specific EMS are hypothesized to remain latent until they are activated by specific dysfunctional cognitive coping style, such as co-rumination, that is relevant for these schemas. When activated, such EMSs lead to the development of trait anxiety in response to co-rumination.

Since anxiety is known to present differently and more frequently in females relative to males, and co-rumination is associated with more negative symptomatology in girls, 
we also examined potential sex differences in the proposed mediation model. Females have been found to report higher levels of co-rumination than males, and co-rumination has been found to predict higher anxiety levels in females but not in males. ${ }^{2,6}$

\section{Materials and methods Participants}

Data in this study partially overlapped with previous research. ${ }^{56}$ Participants included 461 Italian subjects, of whom $84.4 \%$ were undergraduate students. They were, on average, 23.9 years $(\mathrm{SD}=6.9)$ old, with an average of 13.5 years of education ( $\mathrm{SD}=1.9$ ). Study participants were recruited through several types of advertisements, contributed on a voluntary basis, as described in detail previously. ${ }^{56}$

\section{Ethics approval and consent to participate}

The ethics committee of the Department of Psychological Sciences, Health and Territory, University of Chieti, Italy, reviewed the methods of the study and approved it.

All procedures performed in studies involving human participants were in accordance with the ethical standards of the institutional and/or national research committee and with the 1964 Declaration of Helsinki and its later amendments or comparable ethical standards. Written informed consent was obtained from all individual participants included in the study. Participants were debriefed about the study's purpose and were informed that they could withdraw from participation at any time and without any consequences.

\section{Measures}

All participants completed an anonymous sociodemographic assessment. Immediately after, they were randomly given the following questionnaires: the Italian versions of the YSQ Long Form, third edition, the Co-Rumination Questionnaire (CRQ), and the State Trait Inventory for Cognitive and Somatic Anxiety (STICSA). Full descriptions of additional measures can be found in our previous work. ${ }^{56}$

The YSQ Long Form, third edition ${ }^{13}$ is a self-report questionnaire that measures the 18 EMSs in adults. ${ }^{57,94}$ It comprises 232 items, each of which is a self-descriptive statement on a cognitive maladaptive belief as conceptualized by Young et al's schema theory. Respondents are asked to rate the accuracy of these statements (from 1 "not true at all" to 6 "this describes me perfectly"). ${ }^{13}$ Statements are hierarchically grouped into five domains, each domain representing some combination of unique EMS. A mean score is computed for each cognitive schema, with a higher score corresponding to higher endorsement of a particular maladaptive schema. A schema domain score is obtained by computing the mean of all EMSs that comprise a given domain. Cronbach's $\alpha$ coefficients for this study are reported in Table 2.

The STICSA-trait version ${ }^{46}$ is a 21 -item self-report questionnaire designed to evaluate cognitive (eg, "I feel agonized over my problems") and somatic (eg, "My heart beats fast") symptoms of anxiety. STICSA was developed to address the psychometric limitations of existing measures of anxiety, especially their extensive overlap with depression. ${ }^{58-61}$ For the trait version, individuals rate how often a statement is true in general, from 1 "not at all" to 4 "very much so." In

Table 2 Correlations, reliability, and descriptive statistics for co-rumination, anxiety, and early maladaptive schema questionnaires $(\mathrm{N}=460)$

\begin{tabular}{|c|c|c|c|c|c|c|c|c|c|c|c|}
\hline & \multicolumn{3}{|l|}{ STICSA } & \multicolumn{5}{|l|}{ YSQ } & \multicolumn{3}{|c|}{ Descriptive statistics } \\
\hline & Tot & $\mathbf{S}$ & C & $D / R$ & IA & OD & IL & O/I & $\alpha$ & $\mathbf{M}$ & SD \\
\hline CRQ & $0.207 * * *$ & $0.139 * *$ & $0.227^{* * *}$ & $0.180 * * *$ & $0.265^{* * *}$ & $0.322 * * *$ & $0.204 * * *$ & $0.320 * * *$ & 0.95 & 2.73 & 0.76 \\
\hline STICSA-Tot & & $0.882^{* * *}$ & $0.915^{* * *}$ & $0.573 * * *$ & $0.610 * * *$ & $0.512 * * *$ & $0.474 * * *$ & $0.521 * * *$ & 0.89 & 1.76 & 0.45 \\
\hline STICSA-S & & & $0.616^{* * * *}$ & $0.397 * * *$ & $0.468 * * *$ & $0.370 * * *$ & $0.328 * * *$ & $0.345^{* * * *}$ & 0.78 & 1.64 & 0.44 \\
\hline STICSA-C & & & & $0.617 * * *$ & $0.618 * * *$ & $0.539 * * *$ & $0.510 * * *$ & $0.574 * * *$ & 0.84 & 1.90 & 0.57 \\
\hline YSQ-D/R & & & & & $0.655^{* * *}$ & $0.633 * * *$ & $0.652 * * *$ & $0.683^{* * *}$ & 0.95 & 2.10 & 0.58 \\
\hline YSQ-IA & & & & & & $0.68 I^{* * *}$ & $0.559 * * *$ & $0.613^{* * *}$ & 0.94 & 1.90 & 0.56 \\
\hline YSQ-OD & & & & & & & $0.529 * * *$ & $0.663 * * *$ & 0.92 & 2.45 & 0.68 \\
\hline YSQ-IL & & & & & & & & $0.698 * * *$ & 0.87 & 2.40 & 0.61 \\
\hline YSQ-O/I & & & & & & & & & 0.93 & 2.52 & 0.63 \\
\hline
\end{tabular}

Note: $* * * p<0.001 ; * * p<0.01$.

Abbreviations: C, cognitive subscale; CRQ, Co-Rumination Questionnaire; D/R, Disconnection/Rejection; IA, Impaired Autonomy; IL, Impaired Limits; M, mean; OD, Other-Directedness; O/I, Overvigilance/Inhibition; S, somatic subscale; SD, standard deviation; STICSA, State Trait Inventory of Cognitive and Somatic Anxiety; Tot, total scale; YSQ, Young Schema Questionnaire; $\alpha$, Cronbach's alpha. 
total, the scale comprises the Trait-Somatic (S) subscale and Trait-Cognitive (C) subscale. STICSA-trait has been shown to be stable over repeated administrations during several stress manipulations. ${ }^{46}$ The factor structure has shown strong support, and the total scale and subscales have exhibited high internal consistency, as well as construct consistent correlations in patients, controls, and community samples. ${ }^{46,60,62-65} \mathrm{In}$ spite of high intercorrelations between $\mathrm{S}$ and $\mathrm{C}$, the overlap in variance between the subscales ranges from 0.28 to 0.42 , suggesting that the amount of unique variance captured by each subscale is substantial. The Italian version of STICSA has exhibited good psychometric properties in a sample of middle-aged and older adults. ${ }^{66-68}$ Cronbach's $\alpha$ coefficients for this study are reported in Table 2 .

$\mathrm{CRQ}^{1}$ contains 27 items assessing co-rumination between same-sex friends, which involves excessively discussing personal problems. Each participant was asked to consider the way in which he/she generally interacts with a best friend of the same sex. Each statement was rated on a Likert-type scale (ranging from 1 "not at all true" to 5 "really true"). CRQ exhibited good psychometric properties in a large Italian sample. ${ }^{69}$ Cronbach's $\alpha$ coefficient for this study is reported in Table 2 .

\section{Statistical analysis}

Descriptive statistics, reliability (Cronbach's $\alpha$ ), and correlation analysis (Pearson's correlation coefficients) between STICSA-C and -S, YSQ Long Form, third edition schema domains, and CRQ were examined. Independent $t$-tests were used to assess the effect of sex on all the scales used in this study. Mediation models, using bootstrapped-based confidence intervals, were tested using the SPSS add-on package PROCESS. ${ }^{70}$ Both single mediation analyses (ie, one mediator), as well as multiple mediation analyses, were conducted to examine relationships between co-rumination and anxiety. Multiple mediation was conducted in a stepwise fashion. The single variable with the smallest standardized indirect effect was iteratively removed until only significant mediators remained.

Differently from the most widely used classical causal steps approach, ${ }^{71,72}$ the modern approach to mediation, used in this study, has the following aims. 1) The approach intended to quantify indirect effects, rather than infer the presence of an indirect effect through a set of tests on their constituent paths. 2) It also overcame the sampling distribution assumptions. For example, in the classical approach, normality assumptions of the indirect effect are required to attest the validity of the conclusions through the Sobel test. ${ }^{73}$ In addition, the modern approach allows to make a distinction between mediation and indirect effects. 3) Indirect effects may occur even if there is no evidence that $\mathrm{X}$ (independent variable) and Y (outcome variable) are associated, that is when the direct effect results in being significant. ${ }^{72}$ 4) Again, it allowed comparing specific indirect effects in complex models, which include multiple pathways (ie, several mediators, independent variables, or outcomes), without biases. 5) Finally, moderation and mediation can be combined into either a "moderated mediation" or "mediated moderation" model. ${ }^{70,74}$

\section{Results \\ Data screening}

There were no missing data. To examine whether data deviated from normal distributional properties, we looked at skewness and kurtosis statistics. For all variables of interest, skewness was $<1$ (range $=0.07-0.79$ ). The absolute value of kurtosis was also $<1$ (range $=0.07-0.57$ ). There was a single univariate outlier (defined as a subscale $|Z|>3.29$ ); this subject was removed from further analysis. There were no multivariate outliers (defined as Mahalanobis distance $>$ the equivalent of $p<0.001)$.

Descriptive statistics and internal consistencies were computed for the five YSQ schema domains, STICSA (trait total score, TC, and TS), and the CRQ, as well as the intercorrelations among these scales (Table 2). Relationships between co-rumination and all three scales of the STICSA were significant, ranging from 0.14 to 0.23 (all $p$-values $<0.01$ ). As reported previously, the Young domains were modestly correlated with co-rumination. ${ }^{56}$ Associations among the STICSA scales and the schema domains were significant and positive (all $p$-values $<0.001)$, ranging from $0.33(p<0.001$, between STICSA-S and Impaired Limits) to $0.62(p<0.001$, between STICSA-C and Impaired Autonomy). Cronbach's $\alpha$ coefficients were 0.95 for the CRQ and 0.84 and 0.78 , respectively, for the STICSA-C and STICSA-S. All YSQ schema domains had high internal consistency, with Cronbach's $\alpha$ coefficients ranging from 0.87 to 0.95 .

\section{Sex differences}

Mean and standard deviations, group $t$-tests, $p$-values, and effect sizes are provided for each dependent variable by sex in Table 3. Females exhibited significantly higher levels of co-rumination, total anxiety, and somatic anxiety, but there was no difference in cognitive anxiety (Table 3 ). No sex differences were observed on the YSQ schema domains. 


\section{Mediation set-up}

For mediation to exist, there must be 1) a significant $\mathrm{c}$ path: significant correlations between the independent variable (co-rumination) and the dependent variable (total/cognitive/ somatic anxiety); 2) a significant a path: significant correlation between the independent variable (co-rumination) and potential mediator (schema domains); and 3 ) a significant $b$ path: significant correlation between the potential mediator (schema domains) and dependent variable (total/cognitive/ somatic anxiety). If mediation is present, the indirect effect (path ab) from the independent variable (co-rumination) to the dependent variable (total/cognitive/somatic anxiety) through the mediator (schema domains) will be meaningful. Further, inclusion of the indirect effect into the model (ab) will result in either the new $\mathrm{c}$ path $\left(\mathrm{c}^{\prime}\right)$ being nonsignificant or a reduction in magnitude of the new c path (mediations occur).

\section{Potential moderation by sex}

To examine the possible moderating influence of sex on relationships between potential variables along the hypothesized mediational paths, moderation analyses were conducted. The interactions between sex and co-rumination were not significant in predicting any of the schema domains (a paths) nor were the interactions significant between sex and the schema domains in predicting total, somatic, or cognitive anxiety (b paths). The interactions between sex and co-rumination in predicting total, somatic, or cognitive anxiety (c paths) were also not significant. Given the significant main effects of sex on two of the three outcome variables (Table 3), sex was included as a covariate in all subsequent analyses.

\section{Multiple mediation results}

Since all variables met the necessary criteria for mediation, all were included in multiple mediation models to find those variables that best mediated relationships between co-rumination and STICSA-T, STICSA-S, and STICSA-C. Results are displayed in Table 4. Disconnection/Rejection, Impaired Autonomy, and Overvigilance/Inhibition provided the simplest mediation of the relationship between co-rumination and STICSA-T. Similarly, Disconnection/

Table 3 Mean, SDs, independent $t$-test values, $p$-values, and effect size estimates from examination of sex differences

\begin{tabular}{|c|c|c|c|c|c|}
\hline & $\begin{array}{l}\text { Female } \\
(n=254)\end{array}$ & $\begin{array}{l}\text { Male } \\
(n=206)\end{array}$ & $t$ & $p$-value & Cohen's \\
\hline & Mean (SD) & Mean (SD) & & & \\
\hline CRQ & $2.84(0.78)$ & $2.60(0.7 I)$ & 3.39 & $0.001 * *$ & 0.32 \\
\hline STICSA-Tot & $1.81(0.43)$ & $1.70(0.48)$ & 2.40 & $0.017^{*}$ & 0.24 \\
\hline STICSA-S & $1.69(0.42)$ & $1.58(0.47)$ & 2.56 & $0.011 *$ & 0.25 \\
\hline STICSA-C & $1.94(0.55)$ & I.84 (0.59) & 1.81 & 0.071 & 0.18 \\
\hline YSQ-D/R & $2.07(0.54)$ & $2.11(0.63)$ & 0.84 & 0.399 & 0.07 \\
\hline YSQ-IA & $1.94(0.53)$ & $1.89(0.59)$ & 0.92 & 0.359 & 0.09 \\
\hline YSQ-OD & $2.48(0.55)$ & $2.4 I(0.68)$ & 1.35 & 0.179 & 0.11 \\
\hline YSQ-IL & $2.35(0.58)$ & $2.44(0.65)$ & 1.65 & 0.095 & 0.15 \\
\hline YSQ-O/I & $2.48(0.60)$ & $2.57(0.65)$ & 1.53 & 0.127 & 0.14 \\
\hline
\end{tabular}

Notes: $* *_{p}<0.01 . * p<0.05$.

Abbreviations: C, cognitive subscale; CRQ, Co-Rumination Questionnaire; D/R, Disconnection/Rejection; IA, Impaired Autonomy; IL, Impaired Limits; OD, OtherDirectedness; O/I, Overvigilance/Inhibition; S, somatic subscale; SD, standard deviation; STICSA, State Trait Inventory of Cognitive and Somatic Anxiety; Tot, total scale; YSQ, Young Schema Questionnaire.

Table 4 Multiple mediation analyses

\begin{tabular}{lllllll}
\hline DV & $\mathbf{M}$ & $\mathbf{a}$ & $\mathbf{b}$ & $\mathbf{c}$ & $\mathbf{c}^{\prime}$ & axb \\
\hline STICSA-T & YSQ-D/R** & $0.146 \pm 0.035^{* * *}$ & $0.193 \pm 0.043^{* * *}$ & $0.116 \pm 0.027 * * *$ & $0.004 \pm 0.023$ & $0.047 \pm 0.016$ \\
& YSQ-IA*** & $0.194 \pm 0.03 I^{* * *}$ & $0.290 \pm 0.043^{* * *}$ & - & $0.094 \pm 0.020$ \\
& YSQ-O/I* & $0.280 \pm 0.036^{* * *}$ & $0.101 \pm 0.043^{*}$ & - & $0.047 \pm 0.020$ \\
STICSA-S & YSQ-D/R* & $0.146 \pm 0.035^{* * *}$ & $0.131 \pm 0.042^{* *}$ & $0.072 \pm 0.027 * *$ & $-0.001 \pm 0.025$ & $0.033 \pm 0.014$ \\
& YSQ-IA*** & $0.194 \pm 0.03 I^{* * *}$ & $0.281 \pm 0.046 * * *$ & - & $0.093 \pm 0.020$ \\
STICSA-C & YSQ-D/R** & $0.146 \pm 0.035^{* * *}$ & $0.280 \pm 0.054^{* * *}$ & $0.164 \pm 0.033^{* * *}$ & $0.014 \pm 0.027$ & $0.054 \pm 0.017$ \\
& YSQ-IA*** & $0.194 \pm 0.03 I^{* * *}$ & $0.310 \pm 0.054^{* * *}$ & - & $0.080 \pm 0.019$ \\
& YSQ-O/I** & $0.280 \pm 0.036^{* * *}$ & $0.175 \pm 0.052^{* * *}$ & - & $0.065 \pm 0.020$ \\
\hline
\end{tabular}

Notes: ${ }^{* * *} p<0.001$. ${ }^{*} p<0.01$. ${ }^{* *} p<0.05$. All values $=$ estimate \pm standard error (except $Z$ ).

Abbreviations: A, path between IV and mediator; b, path between mediator and DV; c, direct path (ie, path between IV and DV); C, cognitive subscale; D/R, Disconnection/ Rejection; DV, dependent variable (ie, outcome variable); IA, Impaired Autonomy; IL, Impaired Limits; IV, independent variable (ie, predictor); M, proposed mediator; OD, Other-Directedness; O/I, Overvigilance/Inhibition; S, somatic subscale; STICSA, State Trait Inventory of Cognitive and Somatic Anxiety; Tot, total scale; YSQ, Young Schema Questionnaire; $c^{\prime}$, direct path after mediator is included in model; $A \times B$, completely standardized indirect path. 
Rejection and Impaired Autonomy provided the simplest mediation of the relationship between co-rumination and STICSA-S. Comparable to the first model, Disconnection/ Rejection, Impaired Autonomy, and Overvigilance/Inhibition provided the simplest mediation of the relationship between co-rumination and STICSA-C.

\section{Alternative mediation models}

Additionally, because our data were cross-sectional, we tested a series of alternative mediational models to examine the possibility that co-rumination rather than schema domains might serve as a better mediator (Table 5). In the alternative models, co-rumination was introduced as a mediator in the relationship between the schema domains and STICSA total, as well as cognitive and somatic scales, in addition to including sex as a covariate. These alternative models suggest that those presenting high scores on Young's domains, and thus dysfunctional to a significant degree, might be more prone to co-rumination and hence have higher levels of anxiety. While this test cannot control for the cross-sectional nature of the data, it does provide an additional test of model fit. None of the alternative mediational models exhibited significant mediation at the $p<0.001$ level that was used for the single mediation models. Only three of 15 models showed significant mediation at $p<0.05$ and with extremely small effects. Of note, the three models that showed significant conditional mediation involved cognitive anxiety, co-rumination, and Disconnection/Rejection (one of the three) and trait/cognitive anxiety, co-rumination, and Impaired Limits (two of the three). In individual mediation analyses, these three models only exhibited conditional mediation with schema domains as the proposed mediators. In the multiple mediation tests, Impaired Limits was not a unique, significant mediator.

\section{Discussion}

This study investigated whether co-rumination and trait cognitive and somatic anxiety were conceptually linked and whether maladaptive cognitions served as potential paths through which co-rumination may be related to the two dimensions of anxiety in a sample of nonclinical young adults. This study appears to be the first to use the YSQ, which examines maladaptive beliefs at a much deeper level than other available measures, as well as STICSA, which is considered a more pure measure of state and trait anxiety than other commonly used tools. ${ }^{60}$

The results confirmed that both trait cognitive and somatic anxiety, as proposed by Ree et al, ${ }^{46}$ were significantly linked to five maladaptive schema domains, as conceptualized by Young et al. ${ }^{13}$ This result was in line with previous research, which revealed that co-rumination is associated with anxiety. ${ }^{1,2,4-7}$ In addition, co-rumination was significantly associated with all schema domains. Finally, the relation between maladaptive cognitive schemas and trait anxiety was in line with the current literature. For example, Bosmans et $\mathrm{al}^{75}$ emphasized the role of schema domains in explaining the associations of attachment anxiety and avoidance with

Table 5 Alternative mediation analyses of schema domains with varying anxiety scales/subscales

\begin{tabular}{|c|c|c|c|c|c|c|c|}
\hline IV & DV & $\mathbf{M}$ & $\mathbf{a}$ & b & c & $\mathbf{c}^{\prime}$ & $\mathbf{a x b}$ \\
\hline \multirow[t]{3}{*}{ YSQ-D/R } & STICSA-T* & $C R Q$ & $0.243 \pm 0.059 * * *$ & $0.052 \pm 0.024 *$ & $0.449 \pm 0.030 * * *$ & $0.436 \pm 0.03 I^{* * *}$ & $0.107 \pm 0.027$ \\
\hline & STICSA-S & CRQ & $0.243 \pm 0.059 * * *$ & $0.029 \pm 0.025$ & $0.306 \pm 0.033 * * *$ & $0.299 \pm 0.034 * * *$ & $0.009 \pm 0.009$ \\
\hline & STICSA-C* & $C R Q$ & $0.243 \pm 0.069 * * *$ & $0.078 \pm 0.029 * *$ & $0.606 \pm 0.036 * * *$ & $0.587 \pm 0.037^{* * *}$ & $0.034 \pm 0.014$ \\
\hline \multirow[t]{3}{*}{ YSQ-IA } & STICSA-T & CRQ & $0.355 \pm 0.056 * * *$ & $0.022 \pm 0.023$ & $0.495 \pm 0.030 * * *$ & $0.487 \pm 0.032 * * *$ & $0.010 \pm 0.010$ \\
\hline & STICSA-S & CRQ & $0.355 \pm 0.056 * * *$ & $0.001 \pm 0.025$ & $0.37 I \pm 0.033^{* * *}$ & $0.37 I \pm 0.034 * * *$ & $0.000 \pm 0.011$ \\
\hline & STICSA-C & CRQ & $0.355 \pm 0.056 * * *$ & $0.045 \pm 0.029$ & $0.63 I \pm 0.038 * * *$ & $0.615 \pm 0.041 * * *$ & $0.016 \pm 0.010$ \\
\hline \multirow[t]{3}{*}{ YSQ-OD } & STICSA-T & CRQ & $0.389 \pm 0.053^{* * *}$ & $0.021 \pm 0.026$ & $0.375 \pm 0.030 * * *$ & $0.366 \pm 0.032 * * *$ & $0.011 \pm 0.014$ \\
\hline & STICSA-S & CRQ & $0.389 \pm 0.053^{* * *}$ & $0.005 \pm 0.027$ & $0.263 \pm 0.032^{* * *}$ & $0.26 \mathrm{I} \pm 0.034 * * *$ & $0.003 \pm 0.014$ \\
\hline & STICSA-C & CRQ & $0.389 \pm 0.053 * * *$ & $0.040 \pm 0.032$ & $0.497 \pm 0.036 * * *$ & $0.482 \pm 0.039 * * *$ & $0.027 \pm 0.022$ \\
\hline \multirow[t]{3}{*}{ YSQ-IL } & STICSA-T* & $C R Q$ & $0.270 \pm 0.054^{* * *}$ & $0.055 \pm 0.025 *$ & $0.359 \pm 0.029 * * *$ & $0.344 \pm 0.03 I^{* * *}$ & $0.020 \pm 0.010$ \\
\hline & STICSA-S & CRQ & $0.270 \pm 0.054^{* * *}$ & $0.030 \pm 0.026$ & $0.246 \pm 0.033 * * *$ & $0.238 \pm 0.034^{* * *}$ & $0.011 \pm 0.010$ \\
\hline & STICSA-C* & $C R Q$ & $0.270 \pm 0.054 * * *$ & $0.082 \pm 0.030 * *$ & $0.483 \pm 0.034 * * *$ & $0.46 I \pm 0.037^{* * *}$ & $0.024 \pm 0.010$ \\
\hline \multirow[t]{3}{*}{ YSQ-O/I } & STICSA-T & CRQ & $0.402 \pm 0.050 * * *$ & $0.010 \pm 0.0216$ & $0.383 \pm 0.030 * * *$ & $0.379 \pm 0.032^{* * *}$ & $0.006 \pm 0.014$ \\
\hline & STICSA-S & CRQ & $0.402 \pm 0.050 * * *$ & $0.002 \pm 0.027$ & $0.251 \pm 0.032^{* * * *}$ & $0.250 \pm 0.034^{* * * *}$ & $0.001 \pm 0.015$ \\
\hline & STICSA-C & CRQ & $0.402 \pm 0.050 * * *$ & $0.018 \pm 0.030$ & $0.528 \pm 0.037^{* * * *}$ & $0.521 \pm 0.039 * * *$ & $0.008 \pm 0.014$ \\
\hline
\end{tabular}

Notes: ${ }^{* * *} p<0.001$. ${ }^{* *} p<0.01$. ${ }^{*} p<0.05$. All values = estimate \pm standard error (except Z). Italic font indicates the significant path between mediator and DV.

Abbreviations: a, path between IV and mediator; b, path between mediator and DV; c, direct path (ie, path between IV and DV); C, cognitive subscale; D/R, Disconnection/ Rejection; DV, dependent variable (ie, outcome variable); IA, Impaired Autonomy; IL, Impaired Limits; IV, independent variable (ie, predictor); M, proposed mediator; OD, Other-Directedness; O/I, Overvigilance/Inhibition; S, somatic subscale; STICSA, State Trait Inventory of Cognitive and Somatic Anxiety; Tot, total scale; YSQ, Young Schema Questionnaire; c', direct path after mediator is included in model; $\mathrm{A} \times \mathrm{B}$, completely standardized indirect path. 
symptoms of psychopathology, including anxiety. ${ }^{39}$ Also consistent with the literature, ${ }^{2,6}$ there were significant differences by sex in co-rumination, trait anxiety, and somatic anxiety, with females exhibiting significantly higher scores in all variables. There were no sex differences in any of the five schema domains. Further, sex did not serve as a moderator for any of the examined relationships. While females did exhibit significantly higher levels of co-rumination and trait cognitive and somatic anxiety, there was insufficient evidence to state that these differences are due to differential causal pathways. Females are known to exhibit higher levels of rumination. ${ }^{8}$ Thus, it may merely be that adolescent females are co-ruminating more than their male counterparts, resulting in higher levels of trait anxiety for the former.

Multiple mediation analyses, using a stepwise approach, revealed that Disconnection/Rejection and Impaired Autonomy accounted for the most unique variance in the mediational models between co-rumination and anxiety (trait, somatic, and cognitive). Overvigilance/Inhibition was also a significant mediator in the models related to trait and cognitive anxiety. These results suggest that the effects of corumination on anxiety will be most harmful for individuals who have particular maladaptive cognitive schemas. Specific cognitive schemas might create vulnerability that magnifies the adverse effects of co-rumination on trait anxiety. Disconnection/Rejection refers to an expectation that basic needs will not be met by others or that if they are met, they will not be done so predictably. Impaired autonomy refers to minimized expectations that one can manage to function on one's own or the lack of freedom to express valid needs or emotions. ${ }^{13}$ Thus, the role of these maladaptive schemas in mediating co-rumination and trait anxiety might suggest a personality pattern similar to that of Dependent Personality, which has been shown to be associated with panic disorder. ${ }^{76}$ Impaired Autonomy had the highest standardized value for the indirect effect in relation to trait somatic anxiety. This fact may be especially relevant when considering how physical anxiety may manifest in relation to co-rumination. Overvigilance/Inhibition was a significant mediator in the multiple mediation models of co-rumination and trait, as well as cognitive anxiety. This schema exhibited the highest single indirect effect for both total and cognitive anxiety. Overvigilance/Inhibition is often associated with suppression of emotion and impulse, rigidity, and strong expectations regarding behavior and performance. ${ }^{13}$ Accordingly, co-rumination's influence on Overvigilance/Inhibition would seem more consistent with worry, and a potentially predisposing factor for conditions like generalized anxiety. ${ }^{77}$
Co-rumination's persistent focus on problems could serve as a trigger for the activation of these maladaptive cognitive schemas and result in reciprocal reinforcement of the schema domains. On the basis of our findings, it could be hypothesized that individuals with particular anxious predispositions and perhaps the early basis of maladaptive schemas of dependency and negativity, emotional inhibition, hypercriticalness, and punitiveness are prone to more easily activating these maladaptive schemas in the process of co-rumination, something they likely do more than their peers. The process of activating these belief systems during co-rumination may in turn contribute to elevated levels of anxiety. Prior work has emphasized the importance of measuring the impact of aspects of co-rumination on psychopathology. ${ }^{69,78,79}$ Therefore, it would seem that some facets of co-rumination are more useful, or at least less dysfunctional with respect to others. The mediation of the effect of corumination on anxiety suggests that co-rumination's negative, dysfunctional, nonsolution-focused component might consist of Disconnection/Rejection, Impaired Autonomy, and Overvigilance/Inhibition schema contents.

\section{Limitations}

A further limitation is the potential lack of generalizability of these results to clinical conditions and the cross-sectional nature of the study. Although, Rijkeboer and van den $\mathrm{Bergh}^{80}$ have demonstrated that EMSs are comparable in clinical and nonclinical subjects, the proposed mediation model should be investigated in patient samples as well. In addition, all variables studied herein were assessed via self-report measures. ${ }^{47}$

Although cross-sectional studies are particularly appropriate for estimating and exploring the prevalence of a behavior or disease in a specific population and studying multiple outcomes, ${ }^{81}$ they show strong limitations. ${ }^{82}$ One of the restrictions concerns the difficulties to disentangle causes and effects from simple associations. Even within cross-sectional mediation, it is difficult to establish whether an effect is stable across time and determine the temporal precedence (one important condition of causality) ${ }^{83}$ This is particularly true in this study, where a stable trait anxiety was causally inferred by co-rumination behavior. However, the models tested here had exploratively investigated the mediating role played by EMS on the relationship between a dysfunctional coping style and trait cognitive and somatic anxiety. As showed by Rose et al in a longitudinal study using a general measure of anxiety, co-rumination represents a common coping strategy, which predicted and mediated depressive and anxious symptoms, especially among female children 
and adolescents. ${ }^{2}$ Like in a recursive metacognitive model (ie, the ruminative model), co-rumination predicted both an increase of internalizing symptoms and an increase of positive friendship, which in turn contribute to co-rumination. ${ }^{10}$ So, a simple stressful and negative condition is maintained throughout the co-ruminative process, turning into a pervasive anxiety disorder (ie, GAD or SA). This study is not exhaustive; other mediation models can be hypothesized. For example, mediation models could evaluate the state anxiety variable as an outcome. Differently from what has been done here, it would be interesting to evaluate the role of a co-ruminative attitude as a simple response to an anxious state or trait, which triggers the activation of a dysfunctional schema. ${ }^{2,36}$ Longitudinal models would be useful to test the stability over time of specific schema-coping strategies to predict internalizing symptoms, and to explore the presence of bidirectional pathways. ${ }^{36,37}$

Future research should include other methods, such as psychophysiological or behavioral assessment, and observational methods, as suggested elsewhere. ${ }^{84}$ Finally, we examined sex as a factor affecting the association between co-rumination and anxiety in this study. However, we did not examine the potential influence of other sociodemographic factors. Future work should investigate variables such as age, marital status, and education, as well as alternative individual differences, such as cultural memberships or religious group affiliations.

\section{Clinical implications}

Trait anxiety is believed to be a predisposition to the development of anxiety disorders in general, ${ }^{85}$ although levels of trait anxiety are variable across anxiety disorders. ${ }^{86}$ For example, GAD has clear links to trait anxiety (and negative affect/neuroticism), while specific phobias considerably less so (eg, social phobia). Our results show that cognitive anxiety implies the involvement of a further schema domain relative to somatic anxiety in the co-rumination-anxiety link. Of particular interest, the observed schema domain was associated with beliefs of negativity, emotional inhibition, hypercriticalness, and punitiveness. This finding is consistent with current literature, which suggests that cognitive anxiety is an important component of many anxiety disorders. ${ }^{62}$ In any case, the separation of cognitive and somatic symptoms permits examination of prominent components of anxiety and inclusion of a range of anxious conditions.

In light of our findings, practitioners might note whether adolescent clients/patients with anxiety commonly engage in co-rumination and if so, evaluate the extent to which they seem to hold strong beliefs about being rejected/abandoned by others, dependent on others, and/or exhibit features consistent with those of generalized anxiety. Should these themes emerge, they might aid with cognitive case conceptualization and the approach that the practitioner takes to working with a given client/patient.

The present results may also have direct implications for the therapeutic relationship, particularly on the maladaptive communication style engaged by patients during therapeutic setting and/or during interpersonal communication. Maladaptive communication could lead to an increase in psychological distress, rather than its reduction, particularly in those patients who have suffered from the lack of a secure base (ie, those who score high on the Disconnection/Rejection schema domain) and the lack of freedom to express emotions (who score high on the Impaired Limits schema domain). Clinicians could support young clients to redirect time away from co-ruminating habits toward more functional coping mechanisms and more positive approaches to communication. ${ }^{87-89}$

Young et al discuss each EMS's impact on the therapeutic process and propose a recommended treatment approach. ${ }^{13}$ Given the commonality of beliefs that others will not meet their needs and that they may not be able to function on their own, practitioners may wish to expend additional energy to convince clients that they (practitioner) are emotionally available and dependent and to begin discussing the role of termination early in therapy for individuals who co-ruminate and exhibit elevated levels of anxiety. Practitioners might also carefully monitor for early signs of a client/patient preventatively rejecting the therapist. By specifically targeting maladaptive schemas through the therapeutic relationship and via exercises within the social network of the client/ patient, youths may thereby reduce the likelihood that they will progress to a full-on anxiety disorder.

\section{Conclusion}

Overall, our findings provide support for the idea that certain psychopathological processes can be understood in the context of cognitive schemas. ${ }^{90-93}$ Better understanding of the functioning of co-rumination can help fine-tune interventions to face co-rumination-related problems.

\section{Availability of data and materials}

Data are available from the first author upon request.

\section{Acknowledgment}

The authors gratefully acknowledge statistical analysis support from Nicholas T Van Dam. 


\section{Author contributions}

LC designed the study and conducted the statistical analyses. LC, ID, MI, AS, and MB interpreted the data. MB and LC drafted the manuscript. All authors contributed toward data analysis, drafting and revising the paper and agree to be accountable for all aspects of the work.

\section{Disclosure}

The authors report no conflicts of interest in this work.

\section{References}

1. Rose AJ. Co-rumination in the friendships of girls and boys. Child Dev. 2002;73(6):1830-1843.

2. Rose AJ, Carlson W, Waller EM. Prospective associations of co-rumination with friendship and emotional adjustment: considering the socioemotional trade-offs of co-rumination. Dev Psychol. 2007;43(4):1019.

3. Haggard DL, Robert C, Rose AJ. Co-rumination in the workplace: adjustment trade-offs for men and women who engage in excessive discussions of workplace problems. J Bus Psychol. 2011;26(1):27-40.

4. Calmes CA, Roberts JE. Rumination in interpersonal relationships: does co-rumination explain gender differences in emotional distress and relationship satisfaction among college students? Cognit Ther Res. 2008;32(4):577-590.

5. Stone LB, Hankin BL, Gibb BE, Abela JR. Co-rumination predicts the onset of depressive disorders during adolescence. J Abnorm Psychol. 2011;120(3):752.

6. Hankin BL, Stone L, Ann Wright P. Corumination, interpersonal stress generation, and internalizing symptoms: accumulating effects and transactional influences in a multiwave study of adolescents. Dev Psychopathol. 2010;22(1):217-235.

7. Starr LR, Davila J. Clarifying co-rumination: associations with internalizing symptoms and romantic involvement among adolescent girls. JAdolesc. 2009;32(1):19-37.

8. Nolen-Hoeksema S, Wisco BE, Lyubomirsky S. Rethinking rumination. Perspect Psychol Sci. 2008;3(5):400-424.

9. Watkins ER. Constructive and unconstructive repetitive thought. Psychol Bull. 2008;134(2):163-206.

10. Schwartz-Mette RA, Rose AJ. Co-rumination mediates contagion of internalizing symptoms within youths' friendships. Dev Psychol. 2012;48(5):1355-1365.

11. Beck AT, Haigh EA. Advances in cognitive theory and therapy: the generic cognitive model. Annu Rev Clin Psychol. 2014;10:1-24.

12. Beck AT. Thinking and depression: II. Theory and therapy. Arch Gen Psychiatry. 1964;10(6):561-571.

13. Young JE, Klosko JS, Weishaar ME. Schema Therapy: A Practitioner's Guide. New York: Guilford Press; 2003.

14. Piaget J, Warden M. The Language and Thought of the Child. New York: Harcourt Brace; 1926.

15. Young JE. Young Schema Questionnaire—Long Form 3 (YSQ-L3). New York, NY: Schema Therapy Institute; 2003.

16. Halvorsen M, Wang CE, Richter J, et al. Early maladaptive schemas, temperament and character traits in clinically depressed and previously depressed subjects. Clin Psychol Psychother. 2009;16(5):394-407.

17. Nordahl HM, Holthe H, Haugum JA. Early maladaptive schemas in patients with or without personality disorders: does schema modification predict symptomatic relief? Clin Psychol Psychother. 2005;12(2):142-149.

18. Thimm JC. Mediation of early maladaptive schemas between perceptions of parental rearing style and personality disorder symptoms. J Behav Ther Exp Psychiatry. 2010;41(1):52-59.

19. Weishaar, ME, Beck AT. Cognitive theory of personality and personality disorders. In: Strack S, Editor. Differentiating normal and abnormal personality. 2nd ed. New York: Springer;2006:113e135.
20. Riso LP, Froman SE, Raouf M, et al. The long-term stability of early maladaptive schemas. Cognit Ther Res. 2006;30(4):515-529.

21. Jovev M, Jackson HJ. Early maladaptive schemas in personality disordered individuals. J Pers Disord. 2004;18(5):467-478.

22. Lobbestael J, Arntz A, Sieswerda S. Schema modes and childhood abuse in borderline and antisocial personality disorders. $J$ Behav Ther Exp Psychiatry. 2005;36(3):240-253.

23. Hawke LD, Provencher MD. Schema theory and schema therapy in mood and anxiety disorders: a review. J Cogn Psychother. 2011;25(4): $257-276$.

24. Van Vlierberghe L, Braet C, Bosmans G, Rosseel Y, Bögels S. Maladaptive schemas and psychopathology in adolescence: on the utility of Young's schema theory in youth. Cognit Ther Res. 2010;34(4):316-332.

25. Riso LP, du Toit PL, Stein DJ, Young JE. Cognitive Schemas and Core Beliefs in Psychological Problems: A Scientist-Practitioner Guide. Washington, DC: American Psychological Association; 2007.

26. O'Hara B. Cognitive-behavioral treatment of anxiety in late life from a schema-focused approach. Clin Gerontol. 2001;22(3-4):23-36.

27. Glaser BA, Campbell LF, Calhoun GB, Bates JM, Petrocelli JV. The early maladaptive schema questionnaire-short form: a construct validity study. Meas Eval Couns Dev. 2002;35(1):2-13.

28. Schmidt NB, Joiner Jr TE, Young JE, Telch MJ. The schema questionnaire: investigation of psychometric properties and the hierarchical structure of a measure of maladaptive schemas. Cognit Ther Res. 1995;19(3):295-321.

29. Welburn K, Coristine M, Dagg P, Pontefract A, Jordan S. The schema questionnaire - short form: factor analysis and relationship between schemas and symptoms. Cognit Ther Res. 2002;26(4):519-530.

30. Hedley LM, Hoffart A, Sexton H. Early maladaptive schemas in patients with panic disorder with agoraphobia. J Cogn Psychother. 2001;15(2):131-142.

31. Hinrichsen H, Waller G, Emanuelli F. Social anxiety and agoraphobia in the eating disorders: associations with core beliefs. J Nerv Ment Dis. 2004;192(11):784-787.

32. Cockram DM, Drummond PD, Lee CW. Role and treatment of early maladaptive schemas in Vietnam veterans with PTSD. Clin Psychol Psychot. 2010;17(3):165-182.

33. Dutra L, Callahan K, Forman E, Mendelsohn M, Herman J. Core schemas and suicidality in a chronically traumatized population. J Nerv Ment Dis. 2008;196(1):71-74.

34. Balsamo M. Personality and depression: evidence of a possible mediating role for anger trait in the relationship between cooperativeness and depression. Comp Psychiat. 2013;54(1):46-52.

35. Innamorati $\mathrm{M}$, Imperatori $\mathrm{C}$, Meule $\mathrm{A}$, et al. Psychometric properties of the Italian food cravings questionnaire-trait-reduced (FCQ-Tr). Eat Weight Disord. 2015;20(1):129-135.

36. Calvete E, Orue I, Hankin BL. Early maladaptive schemas and social anxiety in adolescents: the mediating role of anxious automatic thoughts. J Anxiety Disord. 2013;27(3):278-288.

37. Calvete E, Orue I, Hankin B. A longitudinal test of the vulnerabilitystress model with early maladaptive schemas for depressive and social anxiety symptoms in adolescents. J Psychopathol Behav. 2015;37(1): 85-99.

38. Kwak K-H, Lee SJ. A comparative study of early maladaptive schemas in obsessive-compulsive disorder and panic disorder. Psychiatry Res. 2015;230(3):757-762.

39. Wilt J, Oehlberg K, Revelle W. Anxiety in personality. Pers Individ Dif. 2011;50(7):987-993.

40. Vautier S, Pohl S. Do balanced scales assess bipolar constructs? The case of the STAI scales. Psychol Assess. 2009;21(2):187-193.

41. Joseph S, Wood A. Assessment of positive functioning in clinical psychology: theoretical and practical issues. Clin Psychol Rev. 2010;30(7): 830-838.

42. Siddaway AP, Taylor PJ, Wood AM. Reconceptualizing anxiety as a continuum that ranges from high calmness to high anxiety: the joint importance of reducing distress and increasing well-being. J Pers Soc Psychol. 2018;144(2):e1-e11. 
43. Innamorati M, Tamburello S, Contardi A, et al. Psychometric properties of the attitudes toward self-revised in Italian young adults. Depress Res Treat. 2013;2013:1-6.

44. Spielberger CD. Assessment of state and trait anxiety: conceptual and methodological issues. South Psychol. 1985;2(4):6-16.

45. Spielberger CD, Gorsuch RL. Manual for the State-Trait Anxiety Inventory (Form Y):("Self-Evaluation Questionnaire"). Palo Alto, CA: Consulting Psychologists Press; 1983.

46. Ree MJ, French D, MacLeod C, Locke V. Distinguishing cognitive and somatic dimensions of state and trait anxiety: development and validation of the State-Trait Inventory for Cognitive and Somatic Anxiety (STICSA). Behav Cogn Psychother. 2008;36(3):313-332.

47. Raymond JG, Steele JD, Seriès P. Modeling trait anxiety: from computational processes to personality. Front Psychiatry. 2017;8:1-19.

48. Koksal F, Power KG. Four Systems Anxiety Questionnaire (FSAQ): a self-report measure of somatic, cognitive, behavioral, and feeling components. J Pers Assess. 1990;54(3-4):534-545.

49. Koksal F, Power KG, Sharp DM. Profiles of DSM III anxiety disorders on the somatic, cognitive, behavioural and feeling components of the four systems anxiety questionnaire. Pers Individ Dif. 1991;12(6) 643-651.

50. Clark LA, Watson D. Tripartite model of anxiety and depression: psychometric evidence and taxonomic implications. J Abnorm Psychol. 1991;100(3):316-336.

51. Himadi WG, Boice R, Barlow DH. Assessment of agoraphobia: triple response measurement. Behav Res Ther. 1985;23(3):311-323.

52. Saariaho TH, Saariaho AS, Karila IA, Joukamaa MI. Early maladaptive schemas in Finnish adult chronic pain patients and a control sample. Scand J Psychol. 2011;52(2):146-153.

53. Saariaho TH, Saariaho AS, Karila IA, Joukamaa MI. Early maladaptive schemas in Finnish adult chronic male and female pain patients. Scand J Pain. 2010;1(4):196-202.

54. Hoehn-Saric R, McLeod DR, Funderburk F, Kowalski P. Somatic symptoms and physiologic responses in generalized anxiety disorderand panic disorder: an ambulatory monitor study. Arch Gen Psychiatry. 2004;61(9):913-921.

55. Koerner N, Tallon K, Kusec A. Maladaptive core beliefs and their relation to generalized anxiety disorder. Cogn Behav Ther. 2015;44(6): 441-455.

56. Balsamo M, Carlucci L, Sergi MR, Murdock KK, Saggino A. The mediating role of early maladaptive schemas in the relation between co-rumination and depression in young adults. PLoS One. 2015; 10(10):e0140177.

57. Saggino A, Balsamo M, Carlucci L, et al. Analysis of the factor structure of the Italian version of the Young Schema Questionnaire L-3 in an Italian clinical and nonclinical sample: preliminary results of a multicenter study. Giornale Italiano di Psicologia. 2017;44(2):445-466.

58. Bieling PJ, Antony MM, Swinson RP. The State-Trait Anxiety Inventory, Trait version: structure and content re-examined. Behav Res Ther 1998;36(7):777-788.

59. Caci H, Baylé FJ, Dossios C, Robert P, Boyer P. The Spielberger Trait Anxiety Inventory measures more than anxiety. Eur Psychiatry. 2003;18(8):394-400.

60. Grös DF, Antony MM, Simms LJ, McCabe RE. Psychometric properties of the State-Trait Inventory for Cognitive and Somatic Anxiety (STICSA): comparison to the State-Trait Anxiety Inventory (STAI). Psychol Assess. 2007;19(4):369-381.

61. Balsamo M, Romanelli R, Innamorati M, Ciccarese G, Carlucci L, Saggino A. The state-trait anxiety inventory: shadows and lights on its construct validity. J Psychopathol Behav Assess. 2013;35(4):475-486.

62. Van Dam NT, Gros DF, Earleywine M, Antony MM. Establishing a trait anxiety threshold that signals likelihood of anxiety disorders. Anxiety Stress Coping. 2013;26(1):70-86.

63. Gros DF, Simms LJ, Antony MM. Psychometric properties of the State-Trait Inventory for Cognitive and Somatic Anxiety (STICSA) in friendship dyads. Behav Ther. 2010;41(3):277-284.
64. Saggino A, Carlucci L, Sergi MR, et al. A validation study of the psychometric properties of the Other as Shamer Scale-2. SAGE Open. 2017;7(2):1-10.

65. Balsamo M, Macchia A, Carlucci L, et al. Measurement of external shame: an inside view. J Pers Assess. 2015;97(1):81-89.

66. Balsamo M, Innamorati M, Van Dam NT, Carlucci L, Saggino A. Measuring anxiety in the elderly: psychometric properties of the state trait inventory of cognitive and somatic anxiety (STICSA) in an elderly Italian sample. Int Psychogeriatr. 2015;27(6):999-1008.

67. Balsamo M, Carlucci L, Sergi MR, et al. A new measure for trait and state anxiety: the state trait inventory of cognitive and somatic anxiety (STICSA). Standardization in an Italian population. Psicoterapia Cognitiva e Comportamentale. 2016;22(2):229-232.

68. Balsamo M, Saggino A. Determining a diagnostic cut-off on the Teate Depression Inventory. Neuropsychiatr Dis Treat. 2014;10(10): 987-995.

69. Balsamo M, Carlucci L, Sergi M, Saggino A. Validazione della versione italiana del Co-Rumination Questionnaire [Validation of the Italian version of the co-rumination questionnaire]. Psicoterapia Cognitiva e Comportamentale. 2016;22(1):13-34. Italian.

70. Hayes AF. Introduction to Mediation, Moderation, and Conditional Process Analysis: A Regression-Based Approach. New York: Guilford Press; 2013.

71. Baron RM, Kenny DA. The moderator-mediator variable distinction in social psychological research: conceptual, strategic, and statistical considerations. J Pers Soc Psychol. 1986;51(6):1173-1182.

72. Hayes AF. Beyond Baron and Kenny: statistical mediation analysis in the new millennium. Commun Monogr. 2009;76(4):408-420.

73. Sobel ME. Asymptotic confidence intervals for indirect effects in structural equation models. Sociol Methodol. 1982;13:290-312.

74. Muller D, Judd CM, Yzerbyt VY. When moderation is mediated and mediation is moderated. J Pers Soc Psychol. 2005;89(6):852-863.

75. Bosmans G, Braet C, Van Vlierberghe L. Attachment and symptoms of psychopathology: early maladaptive schemas as a cognitive link? Clin Psychol Psychother. 2010;17(5):374-385.

76. Reich J, Noyes R Jr, Troughton E. Dependent personality disorder associated with phobic avoidance in patients with panic disorder. $\mathrm{Am}$ J Psychiatry. 1987;144(3):323-326.

77. Newman MG, Liera SJ, Erickson TM, Przeworski A, Castonguay LG. Worry and generalized anxiety disorder: a review and theoretical synthesis of evidence on nature, etiology, mechanisms, and treatment. Annu Rev Clin Psychol. 2013;9:275-297.

78. Byrd-Craven J, Geary DC, Rose AJ, Ponzi D. Co-ruminating increases stress hormone levels in women. Horm Behav. 2008;53(3):489-492.

79. Davidson CL, Grant DM, Byrd-Craven J, Mills AC, Judah MR, Lechner WV. Psychometric properties of the co-rumination questionnaire. Pers Individ Dif. 2014;70:171-175.

80. Rijkeboer MM, van den Bergh H. Multiple group confirmatory factor analysis of the Young Schema-Questionnaire in a Dutch clinical versus non-clinical population. Cognit Ther Res. 2006;30(3):263-278.

81. Mann C. Observational research methods. Research design II: cohort, cross sectional, and case-control studies. Emerg Med J. 2003;20(1): 54-60.

82. Balsamo M, Lauriola M, Saggino A. Work values and college major choice. Learn Individ Differ. 2013;24:110-116.

83. MacKinnon DP, Fairchild AJ, Fritz MS. Mediation analysis. Annu Rev Psychol. 2007;58:593-614.

84. Campbell DT, Fiske DW. Convergent and discriminant validation by the multitrait-multimethod matrix. Psychol Bull. 1959;56(2):81-105.

85. Leonardo ED, Hen R. Anxiety as a developmental disorder. Neuropsychopharmacology. 2008;33(1):134-140.

86. Watson D, Gamez W, Simms LJ. Basic dimensions of temperament and their relation to anxiety and depression: a symptom-based perspective. J Res Pers. 2005;39(1):46-66

87. Landphair J, Preddy T. More than talk: co-rumination among college students. About Campus. 2012;17(3):18-22. 
88. Balsamo M. Anger and depression: evidence of a possible mediating role for rumination. Psychol Rep. 2010;106(1):3-12.

89. Balsamo M, Imperatori C, Sergi MR, et al. Cognitive vulnerabilities and depression in young adults: an ROC curves analysis. Depress Res Treat. 2013;2013:1-8.

90. Baldwin MW, Fehr B, Keedian E, Seidel M, Thomson DW. An exploration of the relational schemata underlying attachment styles: self-report and lexical decision approaches. Pers Soc Psychol B. 1993;19(6):746-746.

91. Waters HS, Waters E. The attachment working models concept: among other things, we build script-like representations of secure base experiences. Attach Hum Dev. 2006;8(3):185-197.
92. Collins NL, Read SJ. Cognitive representations of attachment: the structure and function of working models. In: Bartholomew K, Perlman D, editors. Attachment Processes Inadulthood. London: Jessica Kingsley; 1994:53-92.

93. Bretherton I. Open communication and internal working models: Their role in the development of attachment relationships. In: Thompson RA, editor. Nebraska Symposium on Motivation, 1988: Vol. 36 Socioemotional development. Lincoln: University of Nebraska Press; 1990: $115-182$.

94. Saggino A, Balsamo M, Carlucci L, et al. Psychometric Properties of the Italian Version of the Young Schema Questionnaire L-3: Preliminary Results. Front. Psychol. 2018;9: Article 312.
Psychology Research and Behavior Management

\section{Publish your work in this journal}

Psychology Research and Behavior Management is an international, peerreviewed, open access journal focusing on the science of psychology and its application in behavior management to develop improved outcomes in the clinical, educational, sports and business arenas. Specific topics covered in the journal include: Neuroscience, memory and decision making; Behavior

\section{Dovepress}

modification and management; Clinical applications; Business and sports performance management; Social and developmental studies; Animal studies. The manuscript management system is completely online and includes a very quick and fair peer-review system, which is all easy to use. Visit http://www dovepress.com/testimonials.php to read real quotes from published authors. 